\title{
The influence of pigment proportions and calendering of coated paperboards on dot
}

\author{
gain \\ S. Sönmez ${ }^{1 *}$ Ö. Özden ${ }^{2}$ \\ ${ }^{1}$ Marmara University, School of Applied Sciences, Department of Printing Technologies, Goztepe-34722, Istanbul, \\ Turkey \\ ${ }^{2}$ Istanbul University-Cerrahpaşa, Faculty of Forest, Department of Forest Product Chemistry and Technology, \\ Bahcekoy-34473, Istanbul, Turkey
}

Received, January 2, 2018; Accepted, December 5, 2018

\begin{abstract}
Dot gain is called Tone Value Increase (TVI). Low dot gain and rounder dot shape are important properties to obtain a good print. Dot gain is a measure of how much extra weight a given percent dot or tone has gained on the final printed substrate by comparison to the actual dot area on a press plate. Dot gain value depends on many factors. The interactions of paper, ink and press conditions are important determinates for a good print. In addition, the pigment coating process and calendering conditions have a significant effect on the printability of paperboards. Pigment coating formulations including mineral pigments, binders and additives improve the gloss, brightness, opacity and smoothness of the paperboards. As a result, print quality of paperboards increase. A uniform paperboard surface is needed to obtain a high quality surface smoothness after the coating process. High surface smoothness improves the uniformity of the dot shape and size. Pigment coating formulation parameters; pigment selection, binder selection and binder level influence print quality. The aims of this study - pigment selection and ratio - are to determine the effect on dot gain in lithography printing. To this aim, base paperboards were coated using five pigment coating formulations which included different combinations of kaolin, calcium carbonate and titanium dioxide pigment with a styreneln-butyl acrylate copolymer binder using a bar application. After coating, the samples were air-dried overnight under TAPPI conditions. Then, half of the coated-paperboards were calendered. Tone scales from 1 to $100 \%$ were offset printed using black ink on the uncalendered and calenderedcoated paperboards. Then, from the printed tone scale, the tone area values were measured with the Gretagmacbeth Spectrolino spectrophotometer. These values showed that pigment coating improved the surface optical and physical properties of paperboards. After calendering, the roughness values of coated paperboards decreased. In addition, the obtained dot and line sharpness on calendered-coated paperboards were better than on uncalenderedcoated paperboards. However, the dot gain values of calendered-coated paperboards had fewer dot gains than uncalendered-coated paperboards. It was established that the variation of pigment proportions in the coating formulations had no significant effect on dot gain.
\end{abstract}

Keywords: Pigment, Coating, Calendering, Offset, TVI, Dot gain

\section{INTRODUCTION}

Considerable differences in tone value can occur during both platemaking and printing and they have a detrimental effect on print quality [1]. However, constant halftone value transfer can be achieved in platemaking and in printing by standardization of the offset process [2-3]. Deformations of the halftone dots in the halftone image can very easily lead to dot gain and color shifting. Slurring and doubling are the two most important influential factors when printing [4].

Dot gain/tone value increase $(Z)[5,6]$ is calculated from the area coverage of the film (FF) as a master for platemaking and the tone value (FD) is transferred to/printed on the substrate via the printing form, printing process, and printing units as follows (Eq. 1):

\footnotetext{
* To whom all correspondence should be sent:

E-mail: ssonmez@marmara.edu.tr
}

$$
\mathrm{Z}[\%]=\mathrm{FD}[\%]-\mathrm{FF}[\%]
$$

Using the color control bar black can be determined by measuring the solid and halftone patches (e. g., $40 \%$ or $80 \%$ ) [7].

The halftone areas should have clean, well defined individual dots in prints. A good halftone print is said to have high printing snap [8]. Dot gain refers to the undesirable condition when the printed halftone dots are larger than the size of the dots on the image carrier. Dot gain depends to a large extent on the characteristics of the ink and the pressure in the printing nip [9]. On the part of the paper, the dot gain is greater on uncoated papers than on hard coated papers because of the absorbent nature of the former grades [10]. Similarly, the printing snap is better on coated paper than on uncoated paper [11]. Dot gain essentially depends on the paper's surface and its absorption/ink setting behavior, the ink rheology, 
the blanket and printing pressure [12].

Surface coating improves smoothness, ink receptivity and surface structure [13]. Therefore, the ingredients in the coating formulations have an important part in obtaining good print quality with a high printing brightness, a wide-tonal range, a uniformity of ink transfer, a high optical density of ink and good dot shapes [14].

The quality of the print depends greatly on the preparatory work done in prepress [15], the printing process, the machine engineering employed, and the materials used for creating the printed product such as paper and ink.

\section{EXPERIMENTAL}

\section{Methodology}

This study is divided into three phases: (1) to develop coating, (2) to apply onto base paperboard using \#4 bar, and (3) to characterize the base paperboard coated sample's dot gain properties.

\section{Materials}

A commercial base paperboard was used as the base substrate for coating. The pigment characteristics are given in Table 1. The binders' properties according to commercial firms are given in Table 2.

\section{Coating Formulations and Application Methods}

For this study, five different coatings were prepared with pigments of different ratios and latex. The coating formulation is given in Table 3 . Prepared formulations were coated on base paperboard by a K-Control Coater laboratory coater using \#4 bar. Coating colors were prepared using a dispersion, their dry solid content was $60 \%$ and $\mathrm{pH}$ was 8-9 (ISO 6588:1981). Viscosities of coating colors were measured by a Brookfield viscometer (TAPPI T666 om-91). After mixing for $30 \mathrm{~min}$, $\mathrm{pH}$, percentage of coating solids and viscosity were measured. After the coating process, the coated base paperboards (TAPPI T402) were calendered at calendering pressures of $300 \mathrm{PLI}, 2$-nip smooth side.

Table 1. Mineral pigment properties

\begin{tabular}{|l|c|c|c|c|}
\hline Pigments and binders & Solid $(\%)$ & Particle size $(\mu \mathrm{m})$ & Brightness $(\%)$ & $\mathrm{pH}$ \\
\hline $\begin{array}{l}\text { Kaolin } \\
(\mathrm{BASF}, \text { Nuclay) }\end{array}$ & 68 & $\begin{array}{c}78-82 \% \\
\text { (below } 2 \mu \mathrm{m})\end{array}$ & 88 & 7.5 \\
\hline $\begin{array}{l}\mathrm{CaCO} \\
(\text { Omya, Hydrocarb 90) }\end{array}$ & 76 & $\begin{array}{c}90 \% \\
\text { (below } 2 \mu \mathrm{m})\end{array}$ & 93 & 9.5 \\
\hline $\begin{array}{l}\mathrm{TiO}_{2} \\
(\text { Tronox, R-KB-2) }\end{array}$ & 94 & $0.3 \mu \mathrm{m}$ & 95 & 7.5 \\
\hline
\end{tabular}

Table 2. Binder properties

\begin{tabular}{|l|c|c|c|c|}
\hline Binders & Dry matter $(\%)$ & Viscosity (mPa.s) & Density $\left(\mathrm{g} / \mathrm{cm}^{3}\right)$ & $\mathrm{pH}$ \\
\hline $\begin{array}{l}\text { Latex } \\
\text { (BASF, }\end{array}$ & $50 \pm 1$ & 370 & 1.02 & $8 \pm 0.50$ \\
Acronal S 360 D) & & & & \\
\hline
\end{tabular}

Table 3. Used pigments and binder parts in the formulations

\begin{tabular}{|c|c|c|c|c|c|}
\hline Coating Formulations & F1 & F2 & F3 & F4 & F5 \\
\hline Ingredients & \multicolumn{5}{|c|}{ Dry Parts Added } \\
\hline Kaolin & 50 & 25 & 75 & 30 & 30 \\
\hline $\mathrm{CaCO}_{3}$ & 50 & 75 & 25 & 65 & 60 \\
\hline Titanium dioxide & & & & 5 & 10 \\
\hline Latex & 8 & 8 & 8 & 8 & 8 \\
\hline
\end{tabular}

\section{Paper Testing}

All the coated base paperboards were conditioned for $24 \mathrm{~h}$ at $50 \% \mathrm{RH}$ and $23{ }^{\circ} \mathrm{C}(73.4$ $\left.{ }^{\circ} \mathrm{F}\right)$ before any measurements were made. Paper roughness was measured by PPS ME-90 (1000 Pa, soft backing) based on TAPPI T555-OM-99. 


\section{S. Sönmez, Ö. Özden: The influence of pigment proportions and calendering of coated paperboards on dot gain}

\section{Printing Testing}

The tone scale from 1 to $100 \%$ was printed on the calendered and uncalendered-coated base paperboard's surface with offset printing, using black ink and a screen frequency of $60 \mathrm{lpc}$. The following printing properties were analyzed after the press trial. Dot gains of printed-uncalendered or calendered-coated paperboards were measured using a calibrated Gretagmacbeth Spectrolino spectrophotometer $\left(\mathrm{D}_{50}, 2\right.$-degree observer, UV included, with white backup) according to ISO $12647-2$ just after the printing, $6 \mathrm{~h}, 12 \mathrm{~h}, 18 \mathrm{~h}$ and $24 \mathrm{~h}$ after the printing. For image analysis of screened dots, the line and surface were zoomed 190 times with an optical microscope (Olympus SZ Pt) and then were transferred into a digital platform and analyzed.

\section{RESULTS AND DISCUSSION}

The surface roughness values of paperboard are a specific property of prime importance for the determination of the printability. The surface roughness affects the printing resolution, i.e. the capability to transfer the thinnest printed lines, dots and their combinations without breaks and distortions. Eventually it defines the quality of a final printed product. Lower roughness value proved a good print surface. Increasing the kaolin ratio in the formulations decreased roughness values. After calendering, the roughness values decreased (Figure 1).

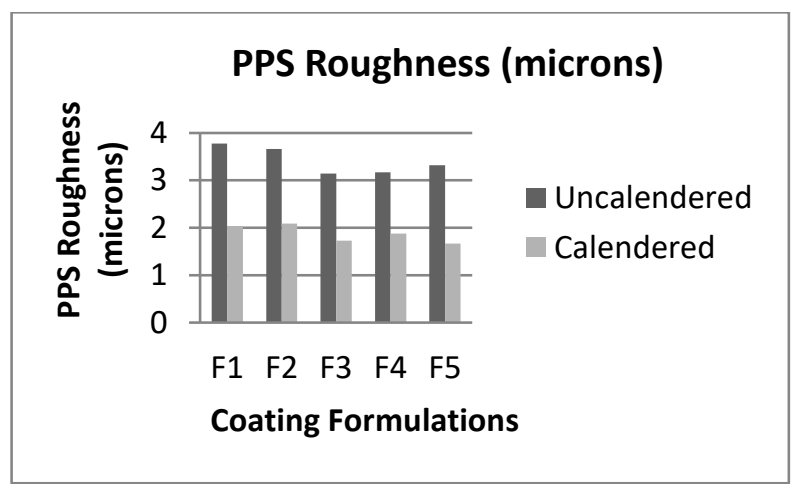

Figure 1. The surface roughness.

In Figures 2-6, for the paperboards overcoated with different formulations that were offset printed, dot areas were determined with a spectrophotometer before and after calendering in the time interval. Line sharpness and surface smoothness views are given at $40 \%$ and $80 \%$ screen tints that were displayed with the optical microscope.

According to ISO standards, the dot gain results of all measurements on printed tone scales' spaces of $40 \%$ and $80 \%$ screen tints are seen to be acceptable; however, uncalendered-coated paperboards have fewer dot gains than calendered-coated paperboards. After the calendering process, the surface roughness values of coated paperboards are decreased, by contrast, dot gains are increased.

The highest dot gain value on $40 \%$ screen tint is obtained with F3 using 75 parts of kaolin and 25 parts of calcium carbonate, which results in an $18 \%$ dot gain. By contrast, when using dot gain values of the $80 \%$ screen tint on all formulations, a dot gain of $12 \%$ was observed.

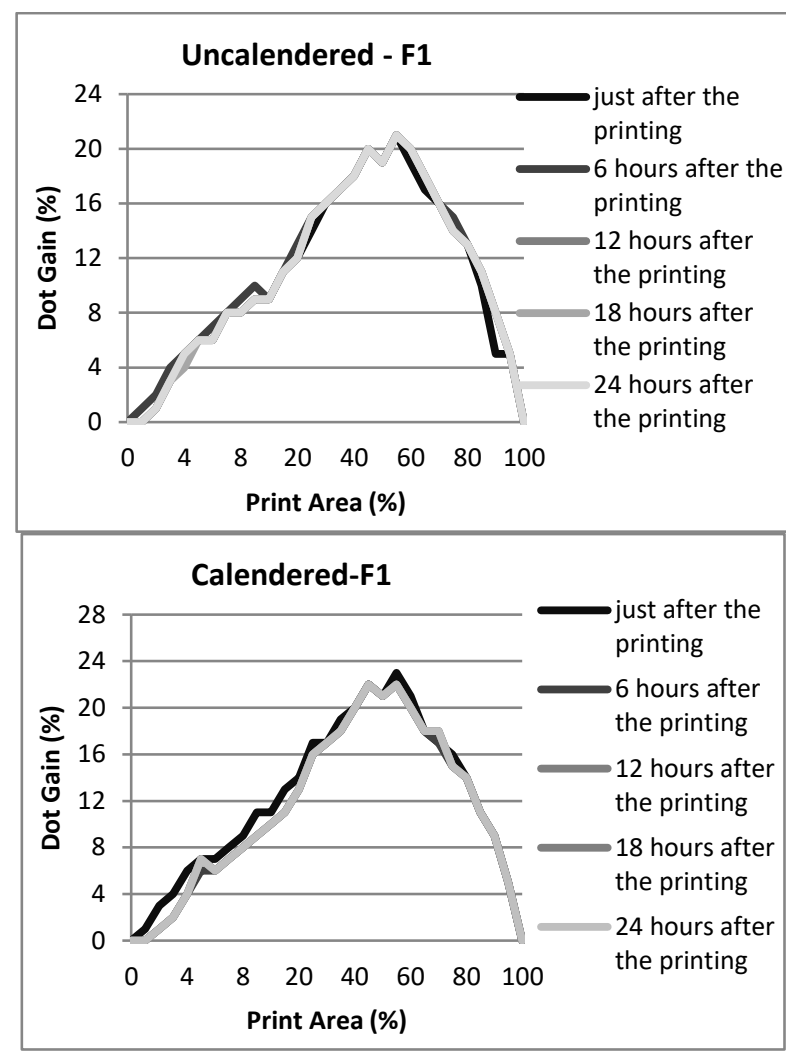

Figure 2. The dot gain values of black printing uncalendered lcalendered-coated paperboards using F1.

Dot gain increased by linking the surface smoothness that affected pigments parameters, calendering conditions and base paperboard properties. Pigments have an important surface characteristic. Especially, their particle shape changed smoothness, ink absorption, brightness, etc. So, the pigment ratio in the coating formulation should be adjusted according to the properties expected from the surface. Calcium carbonate is a coating pigment ensuring good ink absorption, opacity, brightness, smoothness and improved printability [16]. Kaolin pigments in the formulation increased the surface smoothness values of paperboard due to the plate-shaped particles [17]. 

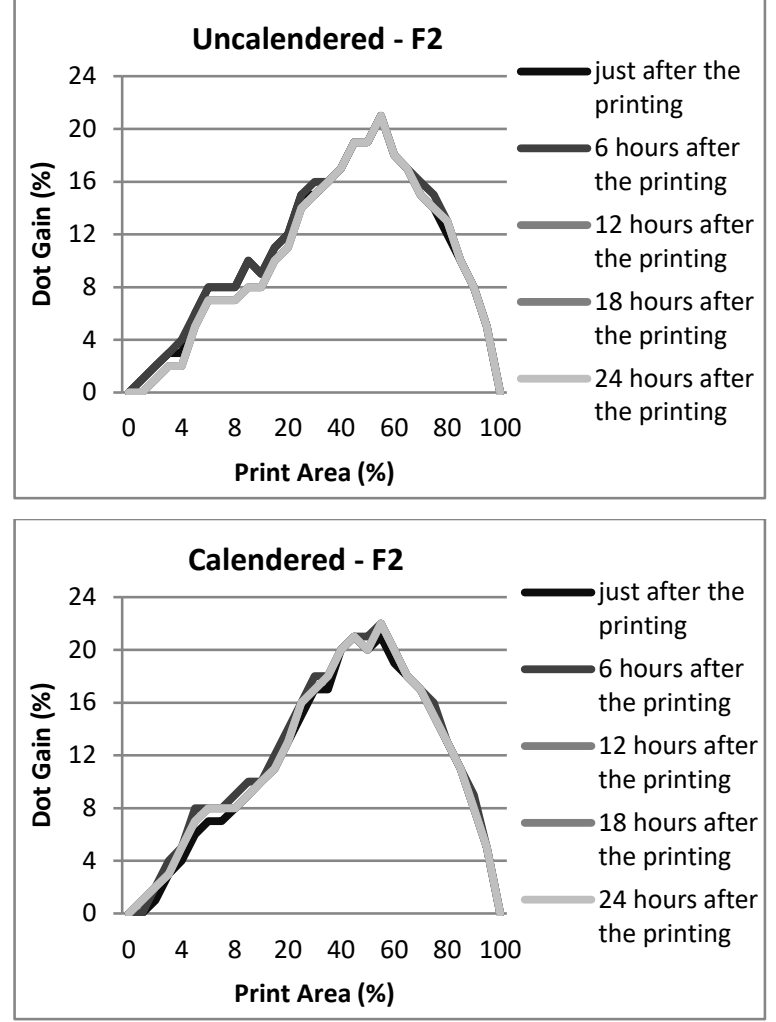

Figure 3. The dot gain values of black printing uncalenderedlcalendered-coated paperboards using F2.
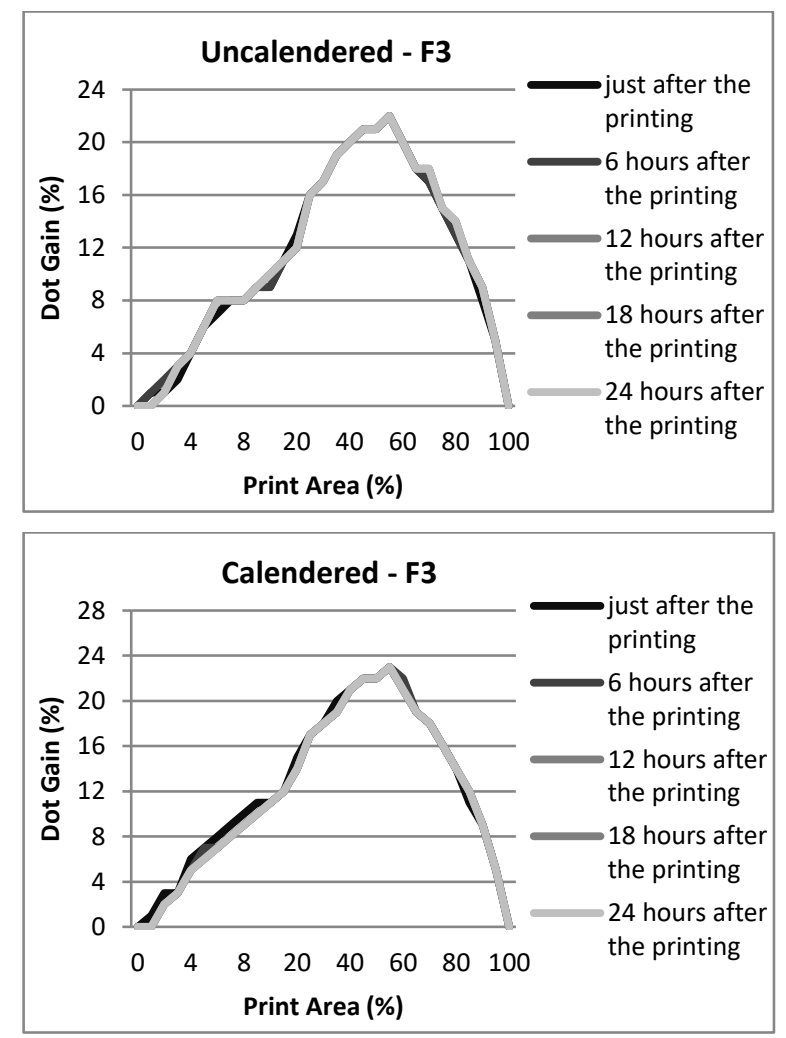

Figure 4. The dot gain values of black printing uncalenderedlcalendered-coated paperboards using F3.
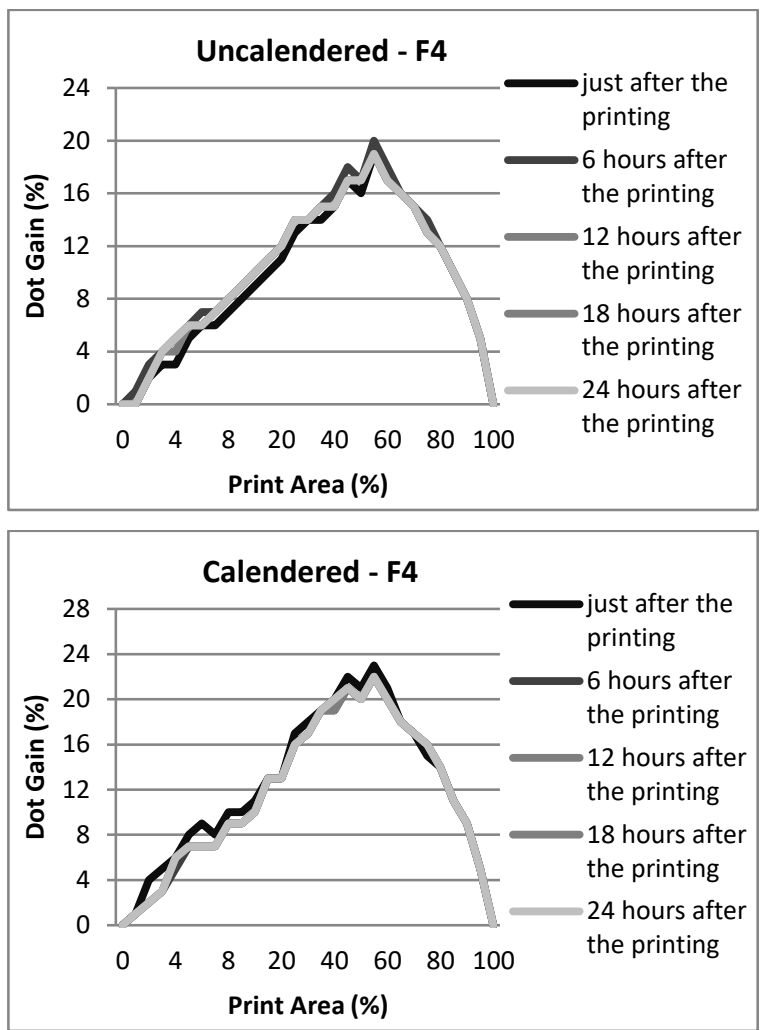

Figure 5. The dot gain values of black printing uncalenderedlcalendered-coated paperboards using F4.
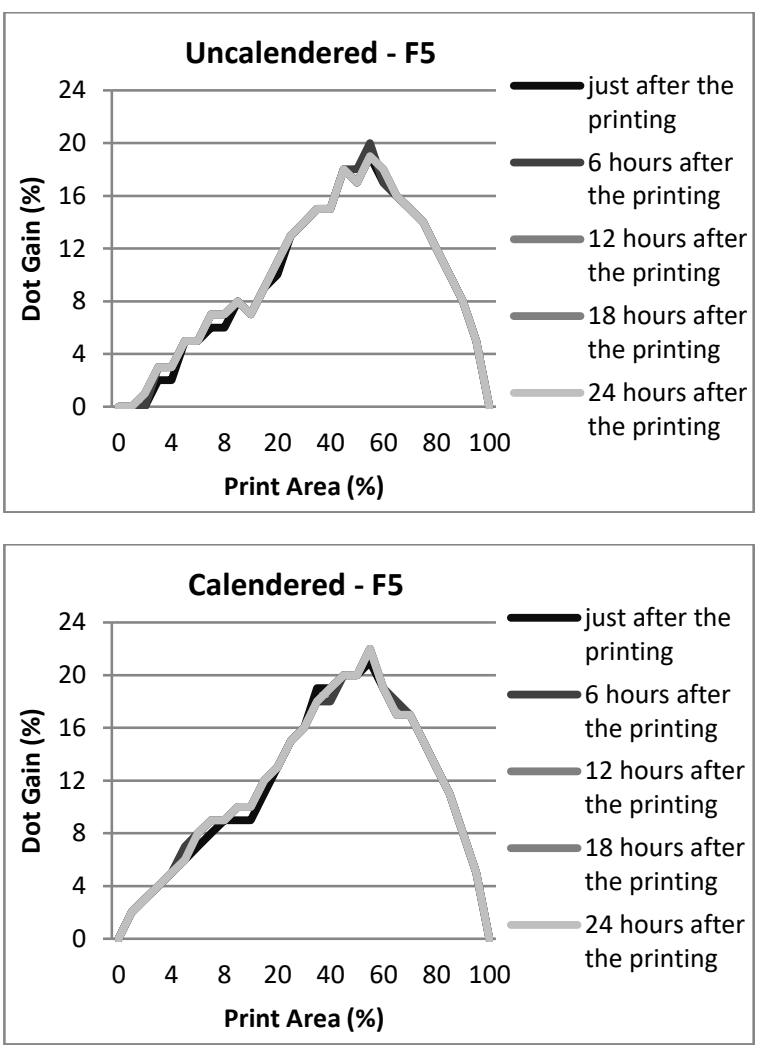

Figure 6. The dot gain values of black printing uncalenderedlcalendered-coated paperboards using F5. 


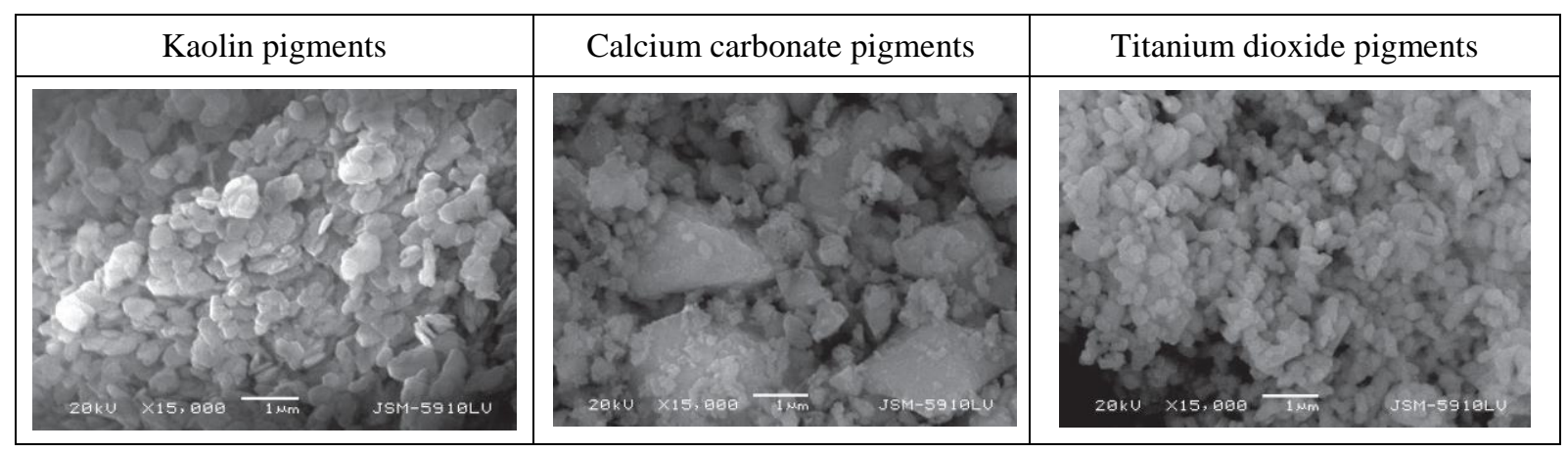

Image 1. SEM images of pigments in the formulations at $\times 15000$ magnification [15]

Image 1 demonstrates the SEM images of pigments in the coating formulations at $15000 \times$ magnification Images 2-6 were observed for the uncalendered and calendered printed $40 \%$ ink tones, $80 \%$ ink tones and paperboard-ink bound with unprinted uncalendered - calendered paperboard surface, zoomed $190 \times$ with microscope. After the calendering process, sharpness is seen in all formulations. These views showed that pigments type and ratios do not affect dot shape and line sharpness.

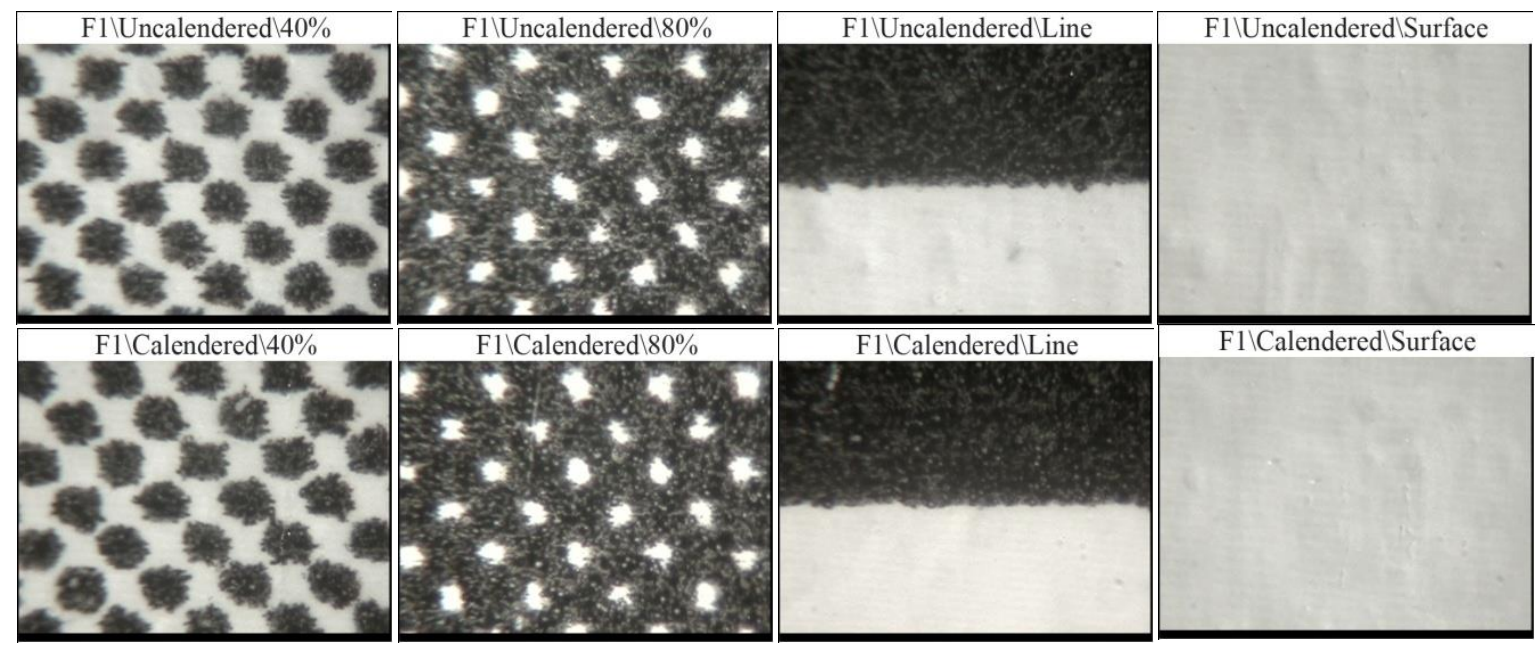

Image 2. The optical microscope views of $40 \%$ dots, $80 \%$ dots, ink-line sharpness and surfaces of uncalenderedlcalendered-coated paperboards using F1

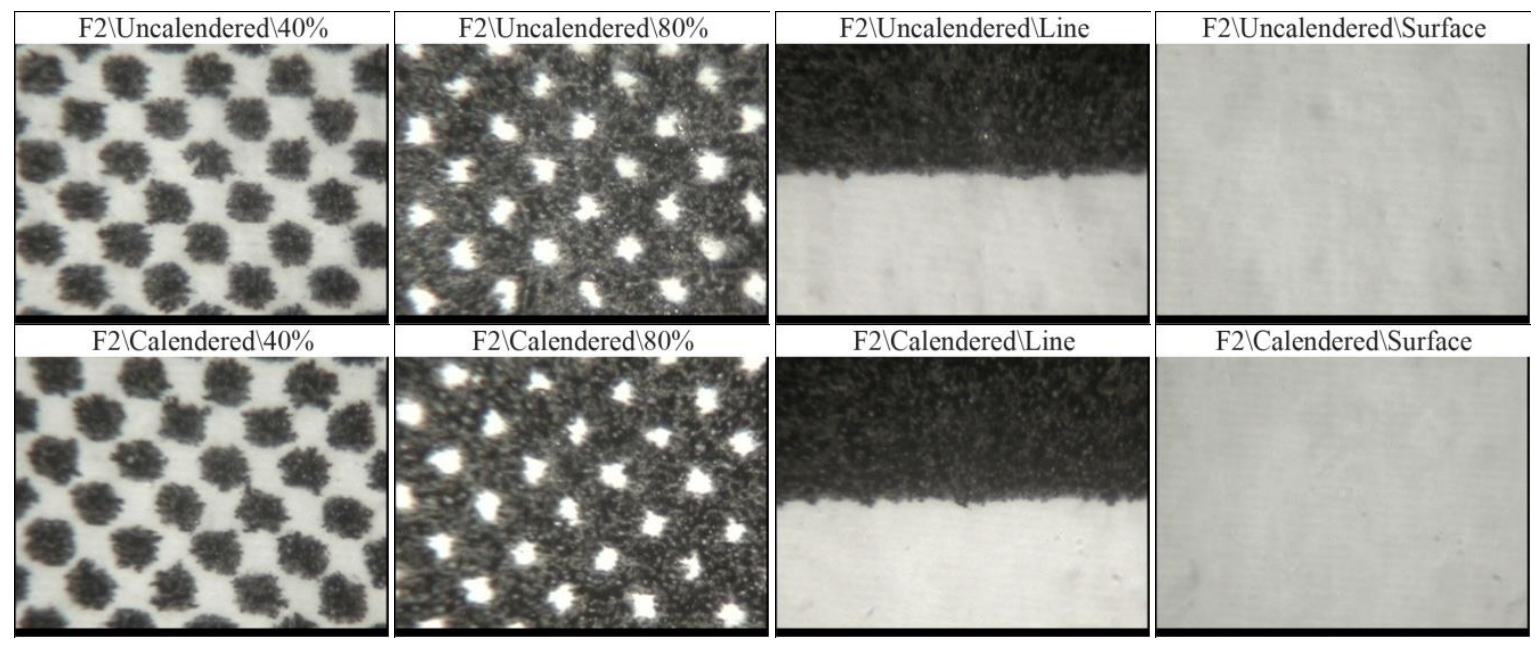

Image 3. The optical microscope views of $40 \%$ dots, $80 \%$ dots, ink-line sharpness and surfaces of uncalenderedlcalendered-coated paperboards using F2 


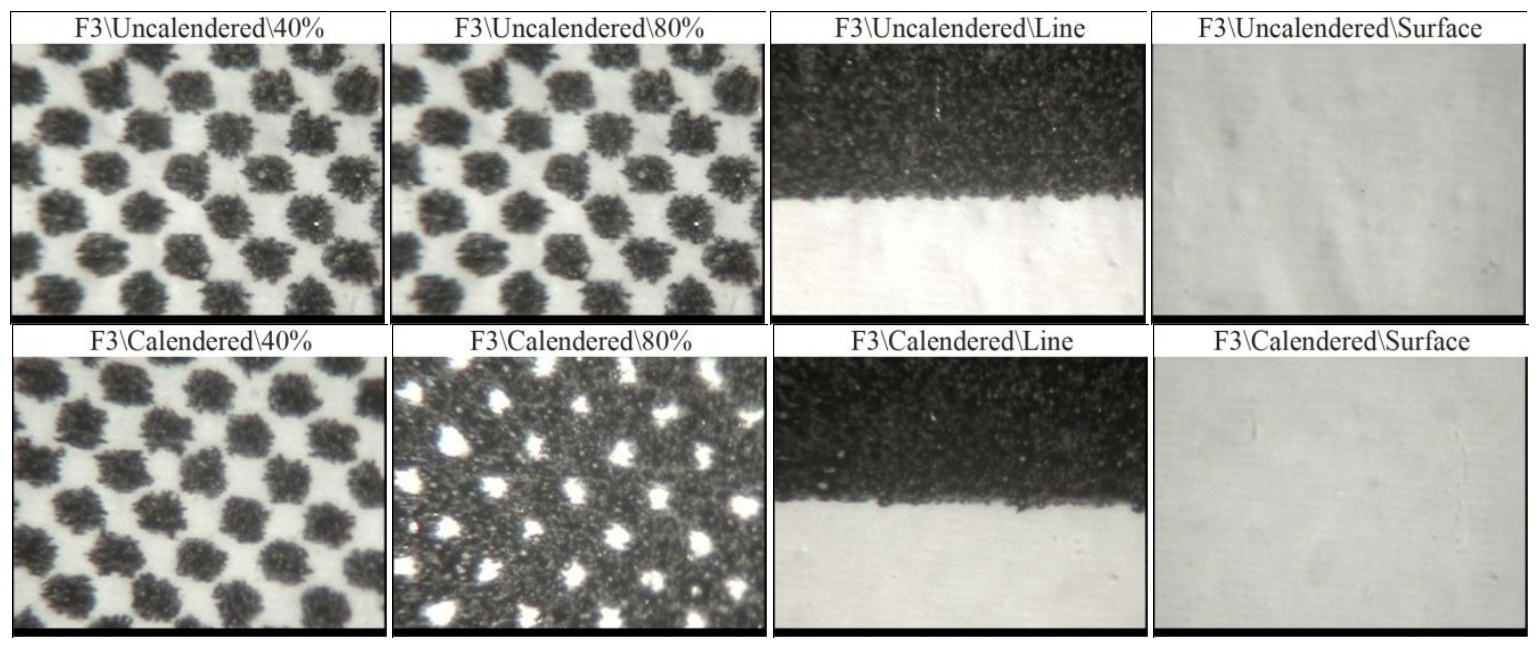

Image 4. The optical microscope views of $40 \%$ dots, $80 \%$ dots, ink-line sharpness and surfaces of uncalenderedlcalendered -coated paperboards using F3.

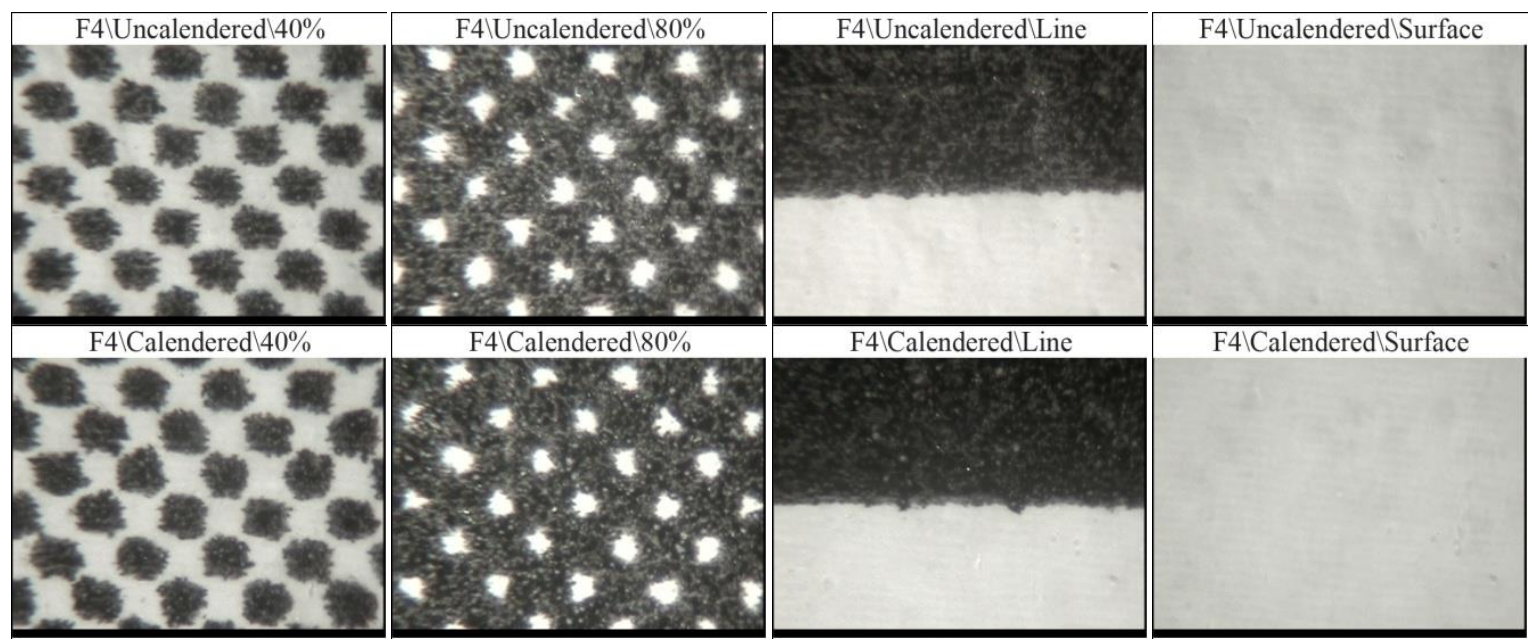

Image 5. The optical microscope views of 40\% dots, $80 \%$ dots, ink-line sharpness and surfaces of uncalenderedlcalendered-coated paperboards using F4.

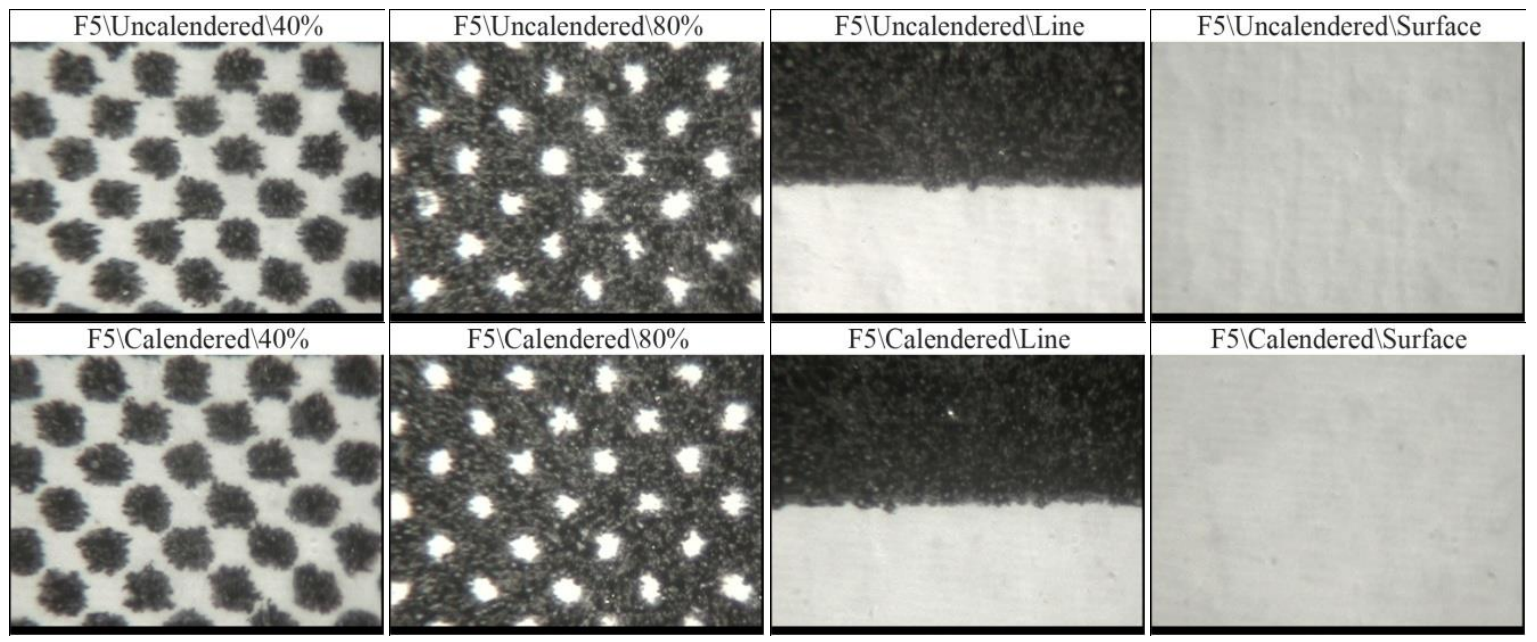

Image 6. The optical microscope views of $40 \%$ dots, $80 \%$ dots, ink-line sharpness and surfaces of uncalenderedlcalendered -coated paperboards using F5.

\section{CONCLUSIONS}

The conclusions of this study are based upon the analysis of data and findings. The specific effect of dot gain of different coating pigments and calendering process is studied. Dot gain is increased linking the surface smoothness that is affected by 
S. Sönmez, Ö. Özden: The influence of pigment proportions and calendering of coated paperboards on dot gain pigments parameters, calendering conditions and base paperboard properties. With kaolin pigments the highest surface smoothness is obtained due to kaolin particular shape. So the image sharpness and definition is increased. Therefore, the contrast is sharper and the color gamut is broader. Dot gain is increasing in the paperboards coated with formulations containing high amounts of kaolin; this increase is acceptable according to ISO standards.

\section{REFERENCES}

1. Y. C. Hsieh, Factors Affecting Dot Gain On Sheet-Fed Offset Presses, Journal of Visual Communications, University of Houston, Houston, TX, 39 (1997).

2. H. N. Dharavath, T. M. Bensen, B. Gaddam, Analysis of Print Attributes of Amplitude Modulated (AM) vs. Frequency Modulated (FM) Screening of Multicolor Offset Printing, Journal of Industrial Technology, 21(3), 2 (2005).

3. A. Verikas, J. Lundström, M. Bacauskiene, A. Gelzinis, Advances in Computational Intelligencebased Print Quality Assessment and Control in Offset Colour Printing, Expert Systems with Applications, 38, 13441 (2011).

4. D. Kumpar, I. Zjakic, I. Bates, Deviation of Deformation of the Screen Elements Through Circulation in the Newspaper Printing, Chapter 34, in: DAAAM International Scientific Book 2010, B. Katalinic (ed.), DAAAM International, Vienna, 2010, p. 357.

5. R. S. M. Abouzeid, A Toner technology \& Image Quality in Electrophotography Printing, The International Design Journal, 3 (2), 1 (2013).

6. F. Miroslav, Separation Model of Colour Regions in A Halftone Print, Journal of Computers \& Graphics, 27 (3), 801 (2003).

7. H. Kipphan, Handbook of Print Media, Springer, Heidelberg, 2001.

8. Y. V. Kuznetsov, Halftoning Myths and Reality.

What is Adaptive to What in Screening?, International Scientific-Practical Conference, Ukraine, 2017, p. 61.

9. R. H. Leach, The Printing Ink Manual, Springer, England, 1988.

10. A. Jurkiewicz, Y. Pyryev, J. Kowalczyk, Printouts' Quality Depending on Too Small Pressure of a Blanket Cylinder Against an Impression Cylinder and a Plate Cylinder in Offset Machine, Challenges of Modern Technology, 4(4), 12 (2013).

11. S. Sonmez, Interactive Effects of Copolymers and Nano-Sized Pigments on Coated Recycled Paperboards in Flexographic Print Applications. Asian Journal of Chemistry, 23(6), 2609 (2011).

12. A. A. Elwan, Influence of Ink Viscosity Level on tone Value Increase in Sheet-fed Offset Printing, International Design Journal, 7(2), 307 (2017).

13. J. S. Preston, A. G. Hiorns, D. J. Parsons, P. J. Heard, Design of Coating Structure for Flexographic Printing, Coating and Graphic Arts Conference, Miami, Florida, USA, 2007, p. 85.

14. H. K. Lee, H.J. Youn, K.H. Lee, C.H. Kim, J.D. Kim, C.Y. Chen, Development of New Coated Linerboard by Combining Condebelt Drying and Curtain Coating Technologies, 63rd Appita Annual Conference and Exhibition, Melbourne, Australia, 2009, p. 203.

15. S. Sonmez, Effects of Calendering on Print Densities of Coated Paperboards, Marmara Journal of Pure and Applied Sciences, 28(4), 164 (2016).

16. J. K. D. Kralj, L. Breèeviæ, G. Falini, Influence of Some Polysaccharides on The Production of Calcium Carbonate Filler Particles, Journal of Crystal Growth, 310(21), 4554 (2008).

17. S. Sonmez, Interactive Effects of Copolymers and Nano-sized Pigments on Coated Recycled Paperboards in Flexographic Print Applications, Asian Journal of Chemistry, 23(6), 2609 (2011). 